\title{
COMPORTAMENTO DE HÍBRIDOS DE MILHO TRANSGÊNICOS E RESPECTIVOS HÍBRIDOS ISOGÊNICOS CONVENCIONAIS EM RELAÇÃO À INFESTAÇÃO \\ DE SPODOPTERA FRUGIPERDA (J. E. SMITH,1727) (LEPIDOPTERA: \\ NOCTUIDAE) EM DUAS LOCALIDADES E ÉPOCAS DE SEMEADURA
}

\author{
J. Nais, A.C. Busoli, M.D. Michelotto
}

Universidade Estadual Paulista, Faculdade de Ciências Agrárias e Veterinárias, Departamento de Fitossanidade, Via de Acesso Prof. Paulo Donato Castellane, s/no, CEP 14884-900, Jaboticabal, SP, Brasil. E-mail: junais_paz@yahoo.com.br

\section{RESUMO}

A lagarta-do-cartucho, Spodoptera frugiperda, é uma das mais importantes pragas do milho. Vários estudos são realizados para o seu manejo, integrando táticas de controle químico, biológico ou através de plantas resistentes. No intuito de oferecer alternativas a um manejo eficiente dessa praga com a mínima utilização de agrotóxicos, a tecnologia das plantas geneticamente modificadas resistentes a insetos tem sido objeto de muitos estudos. Neste trabalho, o objetivo foi avaliar a infestação natural de lagartas de $S$. frugiperda e respectivas injúrias em condições de campo, em híbridos transgênicos de milho comparados aos seus isogenes convencionais, em duas épocas de semeadura e em duas regiões. Os híbridos foram semeados na 'safrinha' de 2010 em Jaboticabal, SP, e no verão em 2010/2011, em Jaboticabal, e Pindorama, SP, em delineamento de blocos ao acaso, com sete tratamentos (híbridos) e quatro repetições. Diferentes níveis de infestação de lagartas ocorreram durante todo o desenvolvimento fenológico das plantas nos híbridos convencionais e nos híbridos geneticamente modificados, com significativas diferenças entre os dois grupos na maioria das avaliações. O híbrido 2B710HX foi o menos infestado com lagartas e o com menor área foliar danificada, o que se conclui que a toxina Cry1F foi a mais efetiva na proteção da planta em relação às demais proteínas tóxicas expressas pelos demais híbridos Bt contra a infestação e os danos promovidos por essa praga, independente da época de semeadura.

PALAVRAS-CHAVE: Controle, lagarta-do-cartucho-do-milho, OGM, transgenia.

\section{ABSTRACT}

BEHAVIOR OF TRANSGENICMAIZE HYBRIDS AND THEIR CONVENTIONAL ISOGENIC COUNTERPARTS IN RELATION TO INFESTATION OF SPODOPTERA FRUGIPERDA (J. E. SMITH, 1727) (LEPIDOPTERA: NOCTUIDAE) AT TWO LOCATIONS AND SOWING DATES. The fall armyworm Spodoptera frugiperda is one of the most important pests of maize. Various studies are conducted for their management, integrating chemical and biological control tactics as well as resistant plants. In order to offer alternatives for an efficient management of this pest with minimal use of pesticides, the technology of genetically modified plants resistant to insects has been widely studied. The aim of the present study was to evaluate the natural infestation of larvae of $S$. frugiperda and their injuries under field conditions in transgenic maize hybrids compared to their conventional isogenic counterparts at two sowing dates and two regions. The hybrids were planted in the "off season" of 2010 in Jaboticabal, SP, Brazil, and the summer of 2010/2011 in Jaboticabal, and Pindorama, SP, in a randomized block with seven treatments (hybrids) and four replications. Different levels of infestation of larvae occurred throughout the phenological development of plants in conventional and genetically modified hybrids with significant differences between the two groups in most evaluations. The hybrid 2B710HX was the least infested with caterpillars and had the least damaged leaf area. It follows that the Cry1F toxin was the most effective in protecting the plant in relation to other toxic proteins expressed by the other Bt hybrids against infestation and damage promoted by this pest, regardless of time of sowing.

KEY WORDS: Control, fall armyworm, GMO, transgenic.. 


\section{INTRODUÇÃO}

O milho (Zea mays L.) é uma das plantas domesticadas pelo homem mais antigas do mundo e é cultivada atualmente na maioria dos países. No Brasil, a área total semeada é cerca de 16,178 milhões de hectares e a produção brasileira para a safra 2011/2012 foi de 72,979 milhões de toneladas (CONPANHIA..., 2012).

As pragas encontram-se dentre os inúmeros fatores que afetam a produtividade das plantas e, entre elas, destaca-sea lagarta-do-cartucho Spodoptera frugiperda (J.E.Smith,1727) (Lepidoptera: Noctuidae), espécie de grande importância, não somente pelos danos que provoca, mas também pela dificuldade $\mathrm{e}$ baixa eficiência do controle químico (BoIçA JUNIOR et al., 1993; Roel; VendRAmim, 2006). Esse inseto ataca preferencialmente o cartucho das plantas de milho, consumindo grande parte da área foliar antes de as folhas se desenvolverem. Oataque intenso ainda nos primeiros estádios de desenvolvimento da planta destrói a região basal do caule formador das novas folhas, podendo levar à morte do colo e todo o conjunto da parte aérea e raízes das plantas (WAQuil et al., 1982). O manejo dessa espécie tem sido realizado principalmente com ouso de produtos químicosque, além de afetar o meio ambiente, também podem promover resistência dos insetos a tais produtos (Lima et al., 2006).

As plantas geneticamentemodificadas resistentes a insetos foram obtidas através de apuradas técnicas de laboratório. Após estudos com a bactéria de solo Bacillus thuringiensis Berliner (Bt), foi introgredidoum dos genes cry nas plantas, dando origem a uma série dehíbridos de milho geneticamente modificados que conferem de moderado a alto grau de resistência da planta a algumas espécies de lepidópteros-praga (ARMSTRONG et al., 1995). O modo de ação dessas toxinas Cry envolve a ligação aos receptores na membrana das células do intestino médio dos insetos suscetíveis, seguido pela formação dos poros, ruptura do epitélio do intestino médio, suspensão da alimentação e morte (BRAVO et al., 2007).

Híbridos de milho com um único gene $\mathrm{Bt}$ tornaram-se disponíveis aos produtores dos EUA no ano de 1996 e expressavam a proteína Cry1Ab (eventos MON 810, Bt-176 e Bt11) para controlar pragas de importância global e econômica, como a broca europeia Ostrinia nubilalis (Hübner), a broca Diatraea grandiosella Dyar, Heliothis virescens (Fabr.) e a lagarta-da-espiga Helicoverpa zea (BoDdIE, 1850) (Milfin, 1996; SiEBERT et al., 2008a).

De acordo com Mendes et al. (2009), estão disponíveis atualmente no Brasil híbridos que expressam toxinas com maior especificidade para os lepidópteros-praga como o Yieldgard ${ }^{\circledR}, \mathrm{oHerculex}{ }^{\circledR}$ e o Agrisure ${ }^{\circledR}$. No Brasil, a liberação dos primeiros híbridos pela CTNBio para a comercialização aconteceu somente em 2008. As informações a respeito do desempenho desses híbridos comerciais no campo são as mais variadas, necessitando de estudos em várias regiões e condições de campo, para avaliar sua eficiência no controle dos lepidópteros-pragas, pois na literatura pouco se encontra sobre avaliações combinadas de infestações de lagartas de $S$. frugiperda e seus respectivos danos causados.

Assim sendo, neste trabalho, objetivou-se avaliar o desempenho de híbridos comerciais de milho convencionais e seus isogênicos híbridos transgênicos que expressam as toxinas Cry1 Ab (tecnologias Yieldgard ${ }^{\circledR}$ e Total Liberty ${ }^{\circledR}$ ) e Cry1F (tecnologia Herculex $\left.{ }^{\circledR}\right)$, com relação à infestação de lagartas de S. frugiperda e injúrias causadas às plantas, em sua fase fenológica de desenvolvimento em dois locais na estação de primavera-verão, e em uma região de cultivo na estação de outono ("safrinha").

\section{MATERIAL E MÉTODOS}

\section{Experimento em Jaboticabal, SP}

Oexperimento foi realizadoemárea experimental da Faculdade de Ciências Agrárias e Veterinárias UNESP - Jaboticabal, SP. Inicialmente foi realizada adubação de semeadura de $250 \mathrm{~kg} \mathrm{ha}^{-1}$ da fórmula 04-14-08 (NPK) e as sementes foram tratadas com imidacloprid (Cruizer 350FS) $600 \mathrm{~mL}$ p.c. por 100 $\mathrm{kg}$ de sementes. A semeadura foi realizada manualmente na densidade de 10-12 sementes/m linear em 2/3/2010 na estação de outono ("safrinha") e na segunda época de semeadura na primavera-verão em 17/11/2010 (safra). Cada parcela foi constituída de 5 linhas de $5 \mathrm{~m}$ de comprimento e $0,80 \mathrm{~m}$ de espaçamento entre linhas. A infestação da lagarta-docartucho foi natural e nenhum outro trato cultural foi realizado na cultura, nem mesmo a aplicação de inseticidas.

Os híbridos comerciais convencionais estudados foram:30F35 (Pionner), 2B710 (Dow AgroSciences) e Impacto (Syngenta). Esses híbridos foram selecionados em função de haver híbridos isogênicos Bt nos quais foram introgredidos os genes cry derivados de $B$. thuringiensis, respectivamente os híbridos 30F35Y que expressa a toxina Cry1Ab (tecnologia Yieldgard $\left.{ }^{\circledR}\right), 30 \mathrm{~F} 35 \mathrm{H}$ e $2 \mathrm{~B} 710 \mathrm{HX}$ que expressam a toxina Cry1F (tecnologia Herculex®) e Impacto $\mathrm{TL}$ que expressa a toxina Cry1 Ab (tecnologia Total Liberty $\left.{ }^{\circledR}\right)$.

As avaliações foram realizadas semanalmente a partir do sétimo DAE até os 56 DAE. Foi avaliada a intensidade de danos causados às folhas das plantas, através da escala visual de notas de danos utilizada por FERNANDEs et al. (2003), adaptada de DAvis et al. 
(1992). No total foram realizadas oito avaliações semanais no período de março/2010 a abril/2010 (safrinha) e oito avaliações semanais no período de novembro/2010 a dezembro/2010 (safra).

Para o estudo da infestação de lagartas nas plantas e dos respectivos danos provocados às folhas, 5 plantas ao acaso por parcela foram arrancadas e transportadas até o Laboratório de Manejo Integrado de Pragas em sacos de papel, onde foram inspecionadas retirando-se as folhas individualmente até chegar ao cartucho das plantas. As lagartas encontradas foram classificadas em pequenas (<10 mm), médias (10 a $20 \mathrm{~mm})$ e grandes $(>20$ $\mathrm{mm}$ ). O delineamento experimental utilizado foi o de blocos ao acaso, com sete tratamentos (híbridos) e quatro repetições.

\section{Experimento em Pindorama, SP - Milho safra 2010/2011}

O experimento foi realizado na APTA, Polo Regional Centro Norte, em Pindorama, SP. A semeadura foi realizada mecanicamente na densidade de 10-12 sementes/m linear, na data de 18/11/2010, com adubação de $300 \mathrm{~kg} \mathrm{ha}^{-1}$ na fórmula NPK 8-28-16, em parcelas constituídas de oito linhas de $10 \mathrm{~m}$ e espaçamento de $0,80 \mathrm{~m}$. As sementes foram tratadas previamente com imidacloprid (Cruiser 350 FS), $600 \mathrm{~mL}$ p.c. para cada $100 \mathrm{~kg}$ de sementes. Os híbridos comerciais são os mesmos do experimento de Jaboticabal, SP, os convencionais 30F35 (Pionner), 2B710 (Dow AgroSciences) e Impacto (Syngenta), e os híbridos transgênicos 30F35Y, 30F35H, 2B710HX e Impacto TL.

A infestação da lagarta-do-cartucho foi natural e nenhum outro trato cultural foi realizado na cultura, nem mesmo a aplicação de inseticidas.

As avaliações foram iniciadas mais tardiamente e realizadas semanalmente a partir de 19 DAE até os $40 \mathrm{DAE}$, de acordo com o inicio de infestação da praga. Foram avaliadas a intensidade de danos causados às folhas e ao cartucho das plantas, através da mesma escala visual de notas de danos utilizada no experimento de Jaboticabal, SP. No total foram realizadas 4 avaliações semanais no período de novembro/2010 a dezembro/2010 (safra). Para o estudo da infestação de lagartas nas plantas e dos respectivos danos provocados às folhas, as coletas foram realizadas da mesma maneira que ocorreram em Jaboticabal, SP.

O delineamento experimental utilizado foi o de blocos ao acaso, com 7 tratamentos (híbridos) e 4 repetições. Todos os dados de ambos os experimentos foram submetidos aos testes de Taylor para homogeneização das médias e redução das variâncias para indicar a melhor transformação dos dados. Estes foram transformados para $\log (x+5)$ e submetidos à Análise de Variância (Teste F) e as médias dos tratamentos comparadas pelo Teste de Tukey, a 5\% de probabilidade, utilizando-se o Programa Computacional SAS 9.1 2002-2003.

\section{RESULTADOS E DISCUSSÃO}

\section{Experimento em Jaboticabal, SP}

Milho safrinha - 2010

Na primeira avaliação (sete DAE) não foram observadas diferenças significativas entre as médias do número de lagartas nos híbridos comerciais e transgênicos. Entretanto, as médias das notas visuais de danos dos híbridos transgênicos foram menores quando comparadas com as médias dos híbridos convencionais. Isto aconteceu porque as lagartas pequenas nos híbridos convencionais se alimentaram continuamente provocando sintomas de folhas raspadas, enquanto que nos híbridos transgênicos as lagartas tiveram morte logo nos dois primeiros instares larvais, e as sobreviventes provocaram menores injúrias nas folhas do cartucho das plantas.

Na segunda avaliação (14 DAE), os dois híbridos com a tecnologia Herculex ${ }^{\circledR}$ que expressam a toxina Cry1F apresentaram diferenças estatísticas significativas em relação ao número de lagartas/ planta com os demais híbridos $\mathrm{Bt}(0,00)$ e não $\mathrm{Bt}$ $(0,20)$ (Tabela 1). Com relação às notas visuais de danos, não foram verificadas diferenças entre os vários híbridos (Tabela 2).

Na quarta avaliação (28 DAE), os quatro híbridos transgênicos continuaram apresentando as menores notas visuais de danos e poucas lagartas pequenas. O híbrido não Bt 30F35 apresentou a maior nota visual de dano $(2,30)$. Esta maior média de nota visual encontrada no híbrido não Bt 30F35 é decorrência da maior infestação de lagartas/planta ocorrida na avaliação da semana anterior (21 DAE) que foi constatada média de 0,40 lagartas pequenas e médias/ planta (Tabela 1).

Na quinta avaliação (35 DAE), os híbridos transgênicos continuaram a apresentar as menores notas visuais de danos nas plantas $(0,25)$, estatisticamente diferentes das médias de notas visuais dos híbridos não Bt $(2,00)$ (Tabela 2). Esses valores de notas visuais de danos são cumulativos, e a cada avaliação podem aumentarcom o tamanho das lagartas que estavam na semana anterior danificando o cartucho das plantas. Em relação ao número de lagartas/planta, não houve diferenças estatísticas entre os híbridos, porém os transgênicos apresentavam infestação de algumas lagartas pequenas, que no processo de alimentação apenas raspavam as folhas, promovendo pouco dano cumulativo às plantas (Tabela 2) . 
Tabela 1 - Número médio de lagartas/planta de S. frugiperda em híbridos convencionais e transgênicos em campo na safrinha. Jaboticabal, SP, Brasil, 2010.

\begin{tabular}{lcccccccc}
\hline Híbridos & 7 DAE & 14 DAE & 21 DAE & 28 DAE & 35 DAE & 42 DAE & 49 DAE & $56 \mathrm{DAE}$ \\
\hline 30F35 & 0,10 A* & 0,20 A & $0,40 \mathrm{~A}$ & $0,10 \mathrm{~A}$ & $0,30 \mathrm{~A}$ & $0,10 \mathrm{~A}$ & $0,10 \mathrm{~A}$ & $0,10 \mathrm{~A}$ \\
2B710 & 0,00 A & 0,05 A & $0,10 \mathrm{~B}$ & $0,20 \mathrm{~A}$ & $0,05 \mathrm{~B}$ & $0,05 \mathrm{~B}$ & $0,05 \mathrm{~B}$ & $0,20 \mathrm{~A}$ \\
Impacto & 0,05 A & $0,20 \mathrm{~A}$ & $0,00 \mathrm{~B}$ & $0,25 \mathrm{~A}$ & $0,15 \mathrm{~A}$ & $0,35 \mathrm{~A}$ & $0,25 \mathrm{~A}$ & $0,15 \mathrm{~A}$ \\
30F35 Y & 0,05 A & $0,05 \mathrm{~A}$ & $0,25 \mathrm{~A}$ & $0,00 \mathrm{~A}$ & $0,00 \mathrm{~B}$ & $0,15 \mathrm{~A}$ & $0,00 \mathrm{~B}$ & $0,00 \mathrm{~B}$ \\
30F35 H & 0,00 A & 0,00 B & $0,10 \mathrm{~B}$ & $0,05 \mathrm{~A}$ & $0,05 \mathrm{~B}$ & $0,20 \mathrm{~A}$ & $0,00 \mathrm{~B}$ & $0,00 \mathrm{~B}$ \\
2B710 HX & 0,00 A & 0,00 B & $0,05 \mathrm{~B}$ & $0,05 \mathrm{~A}$ & $0,00 \mathrm{~B}$ & $0,00 \mathrm{~B}$ & $0,00 \mathrm{~B}$ & $0,00 \mathrm{~B}$ \\
ImpactoTL & 0,05 A & 0,15 A & $0,00 \mathrm{~B}$ & $0,00 \mathrm{~A}$ & $0,00 \mathrm{~B}$ & $0,00 \mathrm{~B}$ & $0,10 \mathrm{~A}$ & $0,05 \mathrm{~A}$ \\
\hline Pr > F & 0,7694 & 0,0022 & 0,0024 & 0,0783 & 0,0091 & 0,0100 & 0,0037 & 0,0085 \\
F & $0,54^{\mathrm{ns}}$ & $5,85^{*}$ & $5,75^{*}$ & $2,37 \mathrm{~ns}$ & $4,30^{*}$ & $4,20^{*}$ & $5,25^{*}$ & $4,36^{*}$ \\
CV & 0,935 & 0,810 & 1,091 & 1,506 & 0,988 & 1,450 & 0,941 & 0,918 \\
\hline
\end{tabular}

*Médias seguidas de mesma letra, nas colunas, não diferem entre si com $p>0,05$.

ns - não significativo.

Tabela 2 - Médias das notas visuais de danos provocados por S. frugiperda em híbridos convencionais e transgênicos em campo na safrinha. Jaboticabal, SP, Brasil, 2010.

\begin{tabular}{lcccccccc}
\hline Híbridos & 7 DAE & 14 DAE & 21 DAE & 28 DAE & 35 DAE & 42 DAE & $49 \mathrm{DAE}$ & $56 \mathrm{DAE}$ \\
\hline 30F35 & 0,40 A* & 0,30 A & $0,70 \mathrm{~A}$ & $2,30 \mathrm{~A}$ & $2,00 \mathrm{~A}$ & $1,30 \mathrm{~A}$ & $1,30 \mathrm{~A}$ & $1,10 \mathrm{~A}$ \\
2B710 & $0,25 \mathrm{~A}$ & $0,00 \mathrm{~A}$ & $1,00 \mathrm{~A}$ & $1,45 \mathrm{~A}$ & $1,70 \mathrm{~A}$ & $0,90 \mathrm{~A}$ & $0,80 \mathrm{~A}$ & $0,60 \mathrm{~A}$ \\
Impacto & $0,40 \mathrm{~A}$ & $0,00 \mathrm{~A}$ & $1,10 \mathrm{~A}$ & $1,50 \mathrm{~A}$ & $1,60 \mathrm{~A}$ & $1,10 \mathrm{~A}$ & $1,20 \mathrm{~A}$ & $1,10 \mathrm{~A}$ \\
30F35 Y & $0,10 \mathrm{~B}$ & $0,05 \mathrm{~A}$ & $0,30 \mathrm{~B}$ & $0,65 \mathrm{~B}$ & $0,40 \mathrm{~B}$ & $0,45 \mathrm{~A}$ & $0,20 \mathrm{~B}$ & $0,40 \mathrm{~A}$ \\
30F35 H & $0,10 \mathrm{~B}$ & $0,00 \mathrm{~A}$ & $0,25 \mathrm{~B}$ & $0,35 \mathrm{~B}$ & $0,25 \mathrm{~B}$ & $0,15 \mathrm{~A}$ & $0,15 \mathrm{~B}$ & $0,05 \mathrm{~B}$ \\
2B710 HX & $0,15 \mathrm{~B}$ & $0,10 \mathrm{~A}$ & $0,25 \mathrm{~B}$ & $0,35 \mathrm{~B}$ & $0,35 \mathrm{~B}$ & $0,10 \mathrm{~B}$ & $0,20 \mathrm{~B}$ & $0,05 \mathrm{~B}$ \\
Impacto TL & $0,10 \mathrm{~B}$ & $0,00 \mathrm{~A}$ & $0,55 \mathrm{~B}$ & $0,45 \mathrm{~B}$ & $0,35 \mathrm{~B}$ & $0,10 \mathrm{~B}$ & $0,35 \mathrm{~A}$ & $0,20 \mathrm{~A}$ \\
Pr > F & 0,0205 & 0,1190 & $<, 0001$ & $<, 0001$ & $<, 0001$ & 0.0034 & 0,0021 & 0,0009 \\
F & $3,52^{*}$ & $2,04^{\text {ns }}$ & $13,55^{*}$ & $16,04^{*}$ & $10,54^{*}$ & $5,34^{*}$ & $5,91^{*}$ & $6,90^{*}$ \\
CV & 1,448 & 1,393 & 1,979 & 2,929 & 4,046 & 4,006 & 3,675 & 3,309 \\
\hline
\end{tabular}

*Médias seguidas de mesma letra, nas colunas, não diferem entre si com p > 0,05.

ns - não significativo.

Nas avaliações seguintes, as diferenças mostraram-se mais distintas. Os híbridos transgênicos apresentaram médias de notas visuais de danos e número de lagartas/planta menores quando comparados aos seus isogenes convencionais (Tabelas 1 e 2). Os menores valores de notas visuais de danos obtidos neste trabalho (menores que um, Tabelas 2, 4, 6), nos híbridos geneticamente modificados, corroboram os resultados encontrados por BUNTIN et al. (2001) e FERNANDES et al. (2003), que também observaram que a infestação de lagartas de $S$. frugiperda em milho geneticamente modificado foi sempremenor em relação aos híbridos não Bt, devido à ação das proteínas tóxicas Cry.

Quando os híbridos Bt e não Bt são comparados entre si, observa-se que o híbrido que apresentou as maiores infestações e médias de notas visuais foi o 30F35. Em contrapartida, os híbridos que obtiveram as menores médias, tanto para as notas visuais de danos como para o número de lagartas/ planta $(0,00$ a 0,6 respectivamente), foram os transgênicos $30 \mathrm{~F} 35 \mathrm{H}$ e $2 \mathrm{~B} 710 \mathrm{HX}$, que possuem a tecnologia Herculex® e expressam a toxina Cry1F.

Milho de safra - 2010/2011

As médias das notas visuais de danos e da infestação de lagartas/ planta apresentadas pelos híbridos indicam queaos sete DAE não apresentavam lagartas e, consequentemente, qualquer sintoma de injúria nas folhas (Tabelas 3 e 4 ).

Na segunda avaliação, aos $14 \mathrm{DAE}$, as plantas apresentavam lagartas na maioria de tamanho médio nos híbridos convencionais com média acima de uma lagarta/planta. Por outro lado, nos híbridos transgênicos, a infestação era menor e, mesmo assim, com presença de lagartas pequenas de $1^{\circ}$ ou $2^{\circ}$ ínstares larvais. Os híbridos mais eficientes no controle foram os que $30 \mathrm{~F} 35 \mathrm{H}, 2 \mathrm{~B} 710 \mathrm{HX}$ e o Impacto $\mathrm{TL}$, respectivamente com médias de 0,$75 ; 0,35$ e 0,65 lagartas pequenas/planta (Tabela 3). 
Tabela 3 - Número médio de lagartas de S. frugiperda em híbridos convencionais e transgênicos em milho na safra de verão. Jaboticabal, SP, Brasil, 2010/2011.

\begin{tabular}{lcccccccc}
\hline Híbridos & $7 \mathrm{DAE}$ & $14 \mathrm{DAE}$ & $21 \mathrm{DAE}$ & $28 \mathrm{DAE}$ & $35 \mathrm{DAE}$ & $42 \mathrm{DAE}$ & $49 \mathrm{DAE}$ & $56 \mathrm{DAE}$ \\
\hline 30F35 & $0,00 \mathrm{~A}^{*}$ & $1,15 \mathrm{AB}$ & $1,00 \mathrm{~A}$ & $1,30 \mathrm{~A}$ & $1,65 \mathrm{~A}$ & $1,20 \mathrm{AB}$ & $0,45 \mathrm{~A}$ & $0,25 \mathrm{~A}$ \\
$2 \mathrm{~B} 710$ & $0,00 \mathrm{~A}$ & $1,25 \mathrm{AB}$ & $1,25 \mathrm{~A}$ & $1,15 \mathrm{~A}$ & $1,20 \mathrm{~A}$ & $0,95 \mathrm{AB}$ & $0,25 \mathrm{AB}$ & $0,20 \mathrm{~A}$ \\
Impacto & $0,00 \mathrm{~A}$ & $1,80 \mathrm{~A}$ & $1,40 \mathrm{~A}$ & $1,45 \mathrm{~A}$ & $1,55 \mathrm{~A}$ & $1,65 \mathrm{~A}$ & $0,20 \mathrm{AB}$ & $0,05 \mathrm{~A}$ \\
& & & & & & & & \\
30F35 Y & $0,00 \mathrm{~A}$ & $0,85 \mathrm{AB}$ & $0,95 \mathrm{~A}$ & $1,15 \mathrm{~A}$ & $1,05 \mathrm{~A}$ & $0,45 \mathrm{~B}$ & $0,20 \mathrm{AB}$ & $0,10 \mathrm{~A}$ \\
30F35 H & $0,00 \mathrm{~A}$ & $0,75 \mathrm{AB}$ & $0,80 \mathrm{~A}$ & $1,45 \mathrm{~A}$ & $1,20 \mathrm{~A}$ & $0,40 \mathrm{~B}$ & $0,10 \mathrm{AB}$ & $0,05 \mathrm{~A}$ \\
2B710 HX & $0,00 \mathrm{~A}$ & $0,35 \mathrm{~B}$ & $0,35 \mathrm{~A}$ & $1,25 \mathrm{~A}$ & $1,75 \mathrm{~A}$ & $0,50 \mathrm{~B}$ & $0,00 \mathrm{~B}$ & $0,05 \mathrm{~A}$ \\
Impacto TL & $0,00 \mathrm{~A}$ & $0,65 \mathrm{~B}$ & $0,80 \mathrm{~A}$ & $1,00 \mathrm{~A}$ & $0,95 \mathrm{~A}$ & $0,80 \mathrm{AB}$ & $0,30 \mathrm{AB}$ & $0,10 \mathrm{~A}$ \\
\hline Pr $>\mathrm{F}$ &. & 0,0082 & 0,1470 & 0,9534 & 0,5934 & 0,0040 & 0,0521 & 0,1891 \\
F &. & $4,20^{*}$ & $1,84^{\mathrm{ns}}$ & $0,25^{\mathrm{ns}}$ & $0,78^{\mathrm{ns}}$ & $4,88^{*}$ & $2,63^{*}$ & $1,66^{\mathrm{ns}}$ \\
$\mathrm{CV}$ &. & 4,287 & 4,803 & 5,677 & 5,594 & 3,928 & 2,042 & 1,468 \\
\hline
\end{tabular}

*Médias seguidas de mesma letra, nas colunas, não diferem entre si com $\mathrm{p}>0,05$.

ns - não significativo.

Tabela 4 - Médias das notas de danos visuais provocados por S. frugiperda em híbridos convencionais e transgênicos em milho na safra de verão. Jaboticabal, SP, Brasil, 2010/2011.

\begin{tabular}{lcccccccc}
\hline Híbridos & $7 \mathrm{DAE}$ & $14 \mathrm{DAE}$ & $21 \mathrm{DAE}$ & $28 \mathrm{DAE}$ & $35 \mathrm{DAE}$ & $42 \mathrm{DAE}$ & $49 \mathrm{DAE}$ & $56 \mathrm{DAE}$ \\
\hline 30F35 & $0,00 \mathrm{~A}^{*}$ & $0,95 \mathrm{~A}$ & $1,55 \mathrm{~A}$ & $2,00 \mathrm{AB}$ & $2,15 \mathrm{AB}$ & $3,25 \mathrm{~A}$ & $2,65 \mathrm{~A}$ & $2,95 \mathrm{~A}$ \\
2B710 & $0,00 \mathrm{~A}$ & $0,85 \mathrm{AB}$ & $1,20 \mathrm{AB}$ & $1,60 \mathrm{AB}$ & $1,80 \mathrm{AB}$ & $3,15 \mathrm{~A}$ & $2,75 \mathrm{~A}$ & $2,40 \mathrm{AB}$ \\
Impacto & $0,00 \mathrm{~A}$ & $1,00 \mathrm{~A}$ & $1,25 \mathrm{AB}$ & $2,15 \mathrm{~A}$ & $2,20 \mathrm{~A}$ & $3,30 \mathrm{~A}$ & $2,85 \mathrm{~A}$ & $2,65 \mathrm{AB}$ \\
& & & & & & & \\
30F35 Y & $0,00 \mathrm{~A}$ & $0,75 \mathrm{AB}$ & $1,00 \mathrm{AB}$ & $1,25 \mathrm{BC}$ & $1,20 \mathrm{BC}$ & $1,80 \mathrm{~B}$ & $2,05 \mathrm{AB}$ & $1,85 \mathrm{BC}$ \\
30F35 H & $0,00 \mathrm{~A}$ & $0,30 \mathrm{CD}$ & $0,40 \mathrm{C}$ & $0,95 \mathrm{CD}$ & $0,90 \mathrm{CD}$ & $0,85 \mathrm{C}$ & $0,75 \mathrm{C}$ & $0,95 \mathrm{CD}$ \\
2B710 HX & $0,00 \mathrm{~A}$ & $0,00 \mathrm{D}$ & $0,35 \mathrm{C}$ & $0,60 \mathrm{D}$ & $0,80 \mathrm{D}$ & $0,75 \mathrm{C}$ & $0,45 \mathrm{C}$ & $0,45 \mathrm{D}$ \\
Impacto TL & $0,00 \mathrm{~A}$ & $0,50 \mathrm{BC}$ & $0,80 \mathrm{BC}$ & $1,00 \mathrm{CD}$ & $1,30 \mathrm{BC}$ & $1,05 \mathrm{C}$ & $1,20 \mathrm{BC}$ & $1,05 \mathrm{CD}$ \\
\hline Pr > F &. & $<, 0001$ & $<, 0001$ & $<, 0001$ & 0,0002 & $<, 0001$ & $<, 0001$ & $<, 0001$ \\
F &. & $17,77^{*}$ & $11,92^{*}$ & $9,52^{*}$ & $8,52^{*}$ & $69,58^{*}$ & $28,57^{*}$ & $18,12^{*}$ \\
CV &. & 1,852 & 2,493 & 3,161 & 3,222 & 2,091 & 2,971 & 3,562 \\
\hline
\end{tabular}

*Médias seguidas de mesma letra, nas colunas, não diferem entre si com $\mathrm{p}>0,05$.

ns - não significativo.

Com relação aos danos causados por estas lagartas, verificaram-se que as notas visuais de danos atribuídas aos híbridos transgênicos 30F35H e 2B710HX foram menores e semelhantes entre si, enquanto os híbridos convencionais foram mais danificados e obtiveram médias maiores. O híbrido 2B710HX apresentou pequenos sinais de injúrias de lagartas pequenas, que não foram nem consideradas de nota igual a um (Tabela 4).

Na terceira avaliação (21 DAE), os híbridos convencionais apresentaram as maiores médias de lagartas/planta, e lagartas de todos os tamanhos (Tabela 3). Por outro lado, o híbrido transgênico 2B710HX apresentou a menor média de infestação $(0,35)$. Considerando-se as médias de notas visuais de injúrias acumuladas aos 21 DAE (Tabela 4), os híbridos 2B710HX e 30F35H foram os que pouquíssimas injúrias sofreram enquanto que o híbrido Impacto TL apresentou o dobro na média de notas visuais. No caso do híbrido Bt 30F35Y, ele já apresentava nota visual de danos mais próximo das médias dos híbridos não $\mathrm{Bt}$, inclusive seu híbrido isogênico 30F35, o mais suscetível nesta avaliação, com média de notas de 1,55 (Tabela 8).

Na quarta avaliação (28 DAE), o híbrido Impacto teve a maior média de nota visual de dano $(2,15)$, enquanto o híbrido transgênico 2B710HXapresentou a menor média $(0,60)$. Para o número de lagartas/ planta, os híbridos não apresentaram diferenças estatísticas entre si, porém, nos híbridos Bt somente foram encontradas lagartas pequenas. Os resultados da quinta avaliação (35 DAE) mostraram que os híbridos convencionais apresentavam as maiores médias de notas visuais de danos, enquanto os transgênicos apresentaram as menores médias de notas (Tabela 4). O número de lagartas/planta não diferiu significativamente entre as médias apresentadas pelos híbridos. 
Tabela 5 - Número médio de lagartas de $S$. frugiperda por planta em híbridos convencionais e transgênicos em milho safra de verão. Pindorama, SP, Brasil, 2010/2011.

\begin{tabular}{|c|c|c|c|c|}
\hline Híbridos & $19 \mathrm{DAE}$ & $26 \mathrm{DAE}$ & $33 \mathrm{DAE}$ & $40 \mathrm{DAE}$ \\
\hline 30F35 & $1,65 \mathrm{~A}$ & $1,65 \mathrm{~A}$ & $0,65 \mathrm{AB}$ & $0,85 \mathrm{~A}$ \\
\hline 2B710 & $1,80 \mathrm{~A}$ & $1,77 \mathrm{~A}$ & $1,15 \mathrm{~A}$ & $1,50 \mathrm{~A}$ \\
\hline Impacto & $1,05 \mathrm{~A}$ & $1,15 \mathrm{~A}$ & $1,10 \mathrm{~A}$ & $0,95 \mathrm{~A}$ \\
\hline 30F35 Y & $1,45 \mathrm{~A}$ & $1,44 \mathrm{~A}$ & $0,50 \mathrm{AB}$ & $0,50 \mathrm{~A}$ \\
\hline 30F35 H & $1,35 \mathrm{~A}$ & $1,40 \mathrm{~A}$ & 0,15 B & $0,10 \mathrm{~A}$ \\
\hline 2B710 HX & $1,55 \mathrm{~A}$ & $1,50 \mathrm{~A}$ & 0,05 B & $0,10 \mathrm{~A}$ \\
\hline Impacto TL & $1,20 \mathrm{~A}$ & $1,20 \mathrm{~A}$ & $0,25 \mathrm{~B}$ & $0,10 \mathrm{~A}$ \\
\hline $\operatorname{Pr}>F$ & 0,8232 & 0,8233 & 0,0004 & 0,018 \\
\hline F & $0,47^{\mathrm{ns}}$ & $0,47^{\mathrm{ns}}$ & $7,62^{*}$ & $3,47^{\mathrm{ns}}$ \\
\hline $\mathrm{CV}$ & 6,379 & 6,379 & 3,327 & 5,679 \\
\hline
\end{tabular}

*Médias seguidas de mesma letra, nas colunas, não diferem entre si com $\mathrm{p}>0,05$.

ns - não significativo.

Tabela 6 - Médias das notas de danos visuais provocados por S. frugiperda em híbridos convencionais e transgênicos em milho safra de verão. Pindorama, SP, Brasil, 2010/2011.

\begin{tabular}{|c|c|c|c|c|}
\hline Híbridos & $19 \mathrm{DAE}$ & $26 \mathrm{DAE}$ & $33 \mathrm{DAE}$ & $40 \mathrm{DAE}$ \\
\hline 30F35 & $2,45 \mathrm{~B}$ & $2,45 \mathrm{~B}$ & $2,35 \mathrm{AB}$ & $2,45 \mathrm{~A}$ \\
\hline 2B710 & $4,50 \mathrm{~A}$ & $4,40 \mathrm{~A}$ & $2,80 \mathrm{~A}$ & $2,60 \mathrm{~A}$ \\
\hline Impacto & $4,20 \mathrm{~A}$ & $4,30 \mathrm{~A}$ & $2,70 \mathrm{~A}$ & $2,70 \mathrm{~A}$ \\
\hline 30F35 Y & $1,95 \mathrm{BC}$ & $1,90 \mathrm{BC}$ & 1,65 B & $1,60 \mathrm{~B}$ \\
\hline 30F35 H & $0,75 \mathrm{C}$ & $0,70 \mathrm{C}$ & $0,70 \mathrm{C}$ & $0,55 \mathrm{C}$ \\
\hline 2B710 HX & $0,90 \mathrm{C}$ & $1,00 \mathrm{C}$ & $0,50 \mathrm{C}$ & $0,50 \mathrm{C}$ \\
\hline Impacto TL & $1,30 \mathrm{BC}$ & $1,20 \mathrm{BC}$ & $0,65 \mathrm{C}$ & $0,55 \mathrm{C}$ \\
\hline $\operatorname{Pr}>F$ & $<, 0001$ & $<, 0001$ & $<, 0001$ & $<, 0001$ \\
\hline $\mathrm{F}$ & $20,20^{*}$ & $20,00^{*}$ & $35,70^{*}$ & $46,85^{*}$ \\
\hline $\mathrm{CV}$ & 4,597 & 4,597 & 2,724 & 2,475 \\
\hline
\end{tabular}

*Médias seguidas de mesma letra, nas colunas, não diferem entre si com p > 0,05.

ns - não significativo.

Os resultados da sexta avaliação (42 DAE) apresentaram as maiores médias de notas visuais de danos nos híbridos convencionais, enquanto os híbridos transgênicos 30F35H, 2B710HX e Impacto TL apresentavam as menores notas (Tabela 4). Pela infestação da praga, os híbridos transgênicos30F35Y, $30 \mathrm{~F} 35 \mathrm{He} 2 \mathrm{~B} 710 \mathrm{HX}$ foram os que tiveram as menores médias, enquanto no híbrido Impacto foi observada maior infestação (Tabela 3). Na sétima avaliação, realizada aos $49 \mathrm{DAE}$, os híbridos convencionais apresentaram as maiores e significativas médias de notas visuais de danos, enquanto nos híbridos transgênicos $30 \mathrm{~F} 35 \mathrm{He} 2 \mathrm{~B} 710 \mathrm{HX}$ foram verificadas as menores médias (Tabela 4). Baseado no número de lagartas/planta verificou-se que o híbrido convencional 30F35 apresentou maior número de lagartas/ planta, enquanto o híbrido transgênico 2B710HX apresentou a menor média (Tabela 3).

Na última avaliação (56 DAE) as médias de infestação de lagartas/ planta nos híbridos não foram significativamente diferentes, sendo que os híbridos transgênicos 30F35Y e 2B710HX e o híbrido não Bt Impacto apresentaram médias iguais a 0,05 (Tabela3). Os híbridos convencionais apresentaram as maiores médias de notas visuais de danos, enquanto que no híbrido 2B710HX foi verificada a menor média de notas visuais (Tabela 4).

No geral, quando se comparam os resultados dos sete híbridos nas duas épocas de semeadura em Jaboticabal, SP, observa-se que os híbridos que foram mais infestados de lagartas e com maiores médias de notas visuais de danos nas folhas foram os convencionais. Em contrapartida, os híbridos que apresentaram as menores infestações de lagartas e menores médias de danos foram os híbridos transgênicos 30F35H e o 2B710HX. Ambos possuem a tecnologia Herculex® e expressam a toxina Cry1F, o que mostra a maior eficiência dessa toxina no controle desta praga.

Desta forma conclui-se que os híbridos trans- 
gênicos possuem diferenças quanto à eficiência na redução dos danos ocasionados pela lagarta-docartucho em função da toxina de suas respectivas proteínas Cry. Por exemplo, na revisão de FrANKENHUYZEN (2009), foram comparados 59 holótipos (toxinas) para 71 espécies de insetos. $\mathrm{O}$ espectro de atividade das proteínas Cry foi mais observado nas espécies da família Lepidoptera, entre elas a espécie S. frugiperda, e foi constatado que a toxina Cry1F foi mais ativa para $S$. frugiperda, enquanto que a proteína Cry1 Ab foi considerada como não ativa, ou de baixa eficiência para a espécie.

O modo de ação da proteína tóxica Cry1F é semelhante às outras Cry1 (BRAvo et al., 2007). A proteína Cry1F, no intestino médio de Heliothis virescens, parece se ligar a pelo menos um sítio de ligação da proteína Cry1Ac(JuRAT-FuENTES; AdANG, 2001; BlANCO et al., 2008), o que pode ter somado mais atividade e determinado o seu melhor desempenho no controle das lagartas de $S$. frugiperda.

Em seus estudos com três diferentes populações de $S$. frugiperda, (uma mexicana, uma colombiana e uma brasileira), MONNERAT et al. (2006) afirmaram que as populações de insetos utilizados em seus estudos evoluíram de forma diferente em relação à suscetibilidade às toxinas Cry específicas. Há diferenças entre as interações toxina-receptor dentro dessas populações. Portanto, a suscetibilidade de $S$. frugiperda a diferentes toxinas Cry deve ser cuidadosamente avaliada no desenvolvimento de estratégias de controle de insetos-pragas, incluindo a implantação de milho geneticamente modificado, em diferentes regiões geográficas.

\section{Experimento em Pindorama, SP (Safra verão - 2010/2011)}

Na primeira avaliação, realizada aos 19DAE, não foram observadas diferenças significativas entre as médias do número de lagartas/planta nos híbridos convencionais e transgênicos (Tabela 5). Por outro lado, as médias das notas visuais de danos dos híbridos transgênicos foram significativamente muito menores quando comparadas com as médias dos híbridos convencionais (Tabela 6). Isto aconteceu porque as lagartas nos híbridos convencionais eram maiores, fase que se alimentam vorazmente provocando injúrias maiores. Enquanto isso, nos híbridos transgênicos as lagartas eram sempre pequenas, que no processo de alimentação apenas raspam a epiderme foliar sem, contudo, causarem perfurações no limbo foliar.

Na segunda avaliação (26DAE), o número médio de lagartas/planta também não diferiu estatisticamente entre os híbridos, porém, os híbridos Bt apresentaram menores infestações. Já em relação às médias de notas visuais de danos, os híbridos convencionais apresentavam médias significativamente bem maiores que os híbridos transgênicos (Tabela 6).

Na terceira avaliação (33 DAE), as médias de lagartas/planta nos híbridos convencionais ainda foram maiores que os apresentados pelos híbridos transgênicos, apesar da infestação natural ter diminuído devido a fatores abióticos, principalmente a precipitação. Os híbridos mais atacados foram o 2B710 e o Impacto. Esse resultado expressa que nos híbridos não Bt já havia pelo menos uma lagarta grande se alimentando do cartucho, ocasionando injúrias às plantas. Já entre os híbridos transgênicos, o híbrido 2B710HX apresentava a menor média de infestação (0,05 lagartas pequenas/planta) (Tabela 5). Em relação às médias de notas visuais de danos, os híbridos convencionais 2B710 e Impacto apresentaram as maiores médias, enquanto os híbridos Bt apresentavam significativamente as menores médias de notas visuais de danos $(0,50$ no híbrido 2B710HX) (Tabela 6).

Para a quarta avaliação, realizada aos 40 DAE, a infestação média delagartas/ planta não foi diferente estatisticamente uns dos outros. Porém, pode-se observar que os híbridos transgênicos apresentaram médias bem menores, em torno de 0,10 lagartas/ planta, enquanto o híbrido mais suscetível, o 2B710, apresentou média de infestação igual a 1,50 lagartas/planta.

No geral, verificando os resultados dos dois métodos de avaliações nas duas épocas de semeaduras de Jaboticabal, e de Pindorama, SP, com os 7 híbridos, observou-se que os híbridos mais infestados de lagartas e com maiores médias de notas visuais de danos foram os convencionais. Em contrapartida, os híbridos que apresentaram as menores médias foram os híbridos transgênicos30F35H eo2B710HX, que possuem a tecnologia Herculex ${ }^{\circledR}$ e expressam a toxina Cry1F. Esses dados corroboram os de WAQuiL et al. (2002), que avaliaram diferentes híbridos que expressavam individualmente as toxinas Cry1 $\mathrm{Ab}$, Cry1Ac, Cry1F e Cry9C e que foram observadas diferenças significativas para as danos foliares com notas visuais variando de 0,1 (híbrido 2722 IMI - Cry1F) a 8,8 (híbridos Max 454R176 - Cry1Ac e Garst 8539 - Cry9C) e com os dados obtidos por Michelotto et al. (2011).

Os híbridos de milho que expressam a toxina Cry1F forneceram controle efetivo da lagarta-docartucho na Argentina, em ensaios de campo em Los Altos, Catamarca. Os índices foram significativamente melhores para os híbridos que expressam a toxina Cry1F em comparação com híbridos de milho não Bt. Os resultados apresentados demonstram que híbridos de milho Cry1F podem servir como uma opção de manejo eficaz para a lagarta-do-cartucho na América do Sul (SIEBERT et al., 2008a). 
As injúrias foliares causadas pelas lagartas nos híbridos $\mathrm{Bt}(\mathrm{Cry} 1 \mathrm{~F})$ atingiram média de notas visuais em torno de 1,30 em comparação com médias de 7,9 para híbridos convencionais, altamente suscetíveis à praga. Esses resultados foram obtidos em ensaios de campo realizados no Sul dos EUA por SIEBERT et al. (2008b) em que os híbridos Bt promoveram significativa proteção às plantas quando expostas à pressão de alta infestação de lagartas de $S$. frugiperda.

Conclui-se que a intensidade de danos nas folhas do cartucho dos híbridos transgênicos foi significativamente menor que os dos híbridos convencionais, frente às infestações naturais de lagartas de $S$. frugiperda. Os híbridos transgênicos $30 \mathrm{~F} 35 \mathrm{H} \mathrm{e}$ 2B710HX (tecnologia Herculex ${ }^{\circledR}$ ), que expressam a toxina Cry1F, foram os mais efetivos na redução da infestação de lagartas nas duas localidades e épocas de semeadura.

\section{AGRADECIMENTOS}

À CAPES pela concessão de bolsa de doutorado concedida à primeira autora.

\section{REFERÊNCIAS}

ARMSTRONG, C.L.; PARKER, G.B.; PERSHING, J.C.; BROWN, S.M.; SANDERS, P.R.; DUNCAN, D.R.; STONE, T.; DEAN, D.A.; DEBOER, D.L.; HART, J.; HOWE, A.R.; MORRISH, F.M.; PAJEAU, M.E.; PETERSEN, W.L.; REICH, B.J.; RODRIGUEZ, R.; SANTINO, C.G.; SATO, S.J.; SCHULER, W.; SIMS, S.R.; STEHLING, S.; TAROCHIONE, L.J.; FROMM, M.E. Field evaluation of European corn borer control in progeny of 173 transgenic corn events expressing an insecticidal protein from Bacillus thuringiensis. Crop Science, v.35, p.550-557, 1995.

BLANCO, C.A.; STORER, N.P.; ABEL, C.A.; JACKSON, R.; LEONARD, R.; LOPEZ, J.JR., PAYNE, G.; SIEGFRIED, B.D.; SPENCER, T.; TERÁN-VARGAS, A.P. Baseline susceptibility of tobacco budworm (Lepidoptera: Noctuidae) to Cry1F toxin from Bacillus thuringiensis. Journal Economic Entomology, v.101, p.168-173, 2008.

BOIÇA JUNIOR, A.L.; GALLI, J.C.; BORTOLI, S.A. DE; RODRIGUES JR., C.; LARA, F.M. Comparação de vinte e quatro genótipos de milho infestados por Spodoptera frugiperda (J.E. Smith, 1797) (Lepidoptera, Noctuidae). Anais da Sociedade Entomológica do Brasil, v.22, n.1, p.31137, 1993

BUNTIN, G.D.; LEE, D.; WILSON, D.M.; MCPHERSON, R.M. Evaluation of Yield Gard transgenic resistance for control of fall armyworm and corn earworm (Lepidoptera: Noctuidae) on corn. Florida Entomologist, v.84, n.1, p.37-42, 2001.
BRAVO, A.; GILL, S.S.; SOBERÓN, M. Mode of action of Bacillus thuringiensis Cry and Cyt toxins and their potential for insect control. Toxicon, v.49, p. 423-435, 2007.

COMPANHIA NACIONAL DE ABASTECIMENTO (Brasil). Acompanhamento de safra brasileira: grãos. $12^{\circ}$ Levantamento. Brasília: CONAB, 2011.

DAVIS, F.M.; NG, S.S.; WILLIAMS, W.P. Visual rating scales for screening whorl-stage corn for resistance to fall armyworm. Mississippi: Agricultural and Forest Experiment Station, 1992. 9p. (Technical Bulletin, 186).

FERNANDES, O.D.; PARRA, J.R.P.; NETO, A.F.; PÍCOLI, R.; BORGATTO, A.F.; DEMÉTRIO, C.G.B. Efeito do milho geneticamente modificado MON810 sobre a lagarta-do-cartucho Spodoptera frugiperda (J. E. Smith, 1797) (Lepidoptera: Noctuidae). Revista Brasileira de Milho e Sorgo, v.2, n.2, p.25-35, 2003.

FRANKENHUYZEN, K. Insecticidal activity of Bacillus thuringiensis crystal proteins Journal of Invertebrate Pathology, v.101, p.1-16, 2009.

JURAT-FUENTES, J.L.; ADANG, M.J. Importance of Cry1 $\delta$-endotoxin domain II loops for binding specificity in Heliothis virescens (L.). Applied and Environmental Microbiology, v.67, p.323-329, 2001.

LIMA, F.W.N.; OHASHI, O.S.; SOUZA, F.R.S.; GOMES, F.S. Avaliação de acessos de milho para resistência a Spodoptera frugiperda (Smith) (Lepidoptera: Noctuidae) em laboratório. Acta Amazonica, v.36, n.2, p.147-150, 2006.

MENDES, S.M.; WAQUIL, J.M.; VIANA, P.A. Manejo integrado de pragas em lavouras plantadas com milho geneticamente modificado com gene bt (Milho Bt). Sete Lagoas: Embrapa Milho e Sorgo, 2009. Disponível em: <http:/ / www.cnpms.embrapa.br/publicacoes/milho_5_ed/ milhoBT.htm>. Acesso em: 3 jan. 2012.

MICHELOTTO, M.D.; FINOTO, E.L.; MARTINS, A.L.M.; DUARTE, A.P. Interação entre transgênicos (Bt) e inseticidas no controle de pragas-chave em híbridos de milho-safrinha. Arquivos do Instituto Biológico, São Paulo, v.78. n.1, p.71-79, 2011. Disponível em: <http:// www.biologico.sp.gov.br/docs/arq/v78_1/michelotto. pdf>. Acesso em: 3 jan. 2012.

MIFLIN, B. A view from industry, In: PERSLEY, G.L. (Ed.). Biotechnology and integrated pest management. Wallingford: CAB International, 1996. p.367-386.

MONNERAT, R.; MARTINS, E.; QUEIROZ, P.; ORDUZ, S.; JARAMILLO, G.; BENINTENDE, G.; COZZI, J.; DOLORES REAL, M.; MARTINEZ-RAMIREZ, A.; RAUSELL, C.; CERÓN, J.; IBARRA, J.E.; RINCONCASTRO, M.C.; ESPINOZA, A.M.; MEZA-BASSO, L.; CABRERA, L.; SANCHEZ, J.; SOBERON, M.; BRAVO, A. Genetic Variability of Spodoptera frugiperda Smith (Lepidoptera: Noctuidae) populations from latin 
america is associated with variations in susceptibility to Bacillus thuringiensis Cry toxins. Applied and Environmental Microbiology, v.72, n.11, p.7029-7035, 2006.

ROEL, A.R.; VENDRAMIM, J.D. Efeito residual do extrato acetato de etila de Trichilia pallida Swartz (Meliaceae) para lagartas de diferentes idades de Spodoptera frugiperda (J.E. Smith, 1797) (Lepidoptera: Noctuidae). Ciência Rural, v.36, n.4, p.1049-1054, 2006.

SIEBERT, M.W.; BABOCK, J.M.; NOLTING, S.; SANTOS, J.J.; ADAMCZYK JR., P.A.; NEESE, J.E.; KING, J.N.; JEKINS, J. McCARTY, G.M.; LORENZ, D.; FROMME, D.; LASSITER, R.B. Efficacy of Cry1F insecticidal protein in maize and cotton for control of fall armyworm (Lepidoptera: Noctuidae). Florida Entomologist, v.91, n.4, p.555-565, 2008a.

SIEBERT, M.W.; TINDALL, K.V.; LEONARD, B.R.; VAN DUYN, J.W.; BABCOCK, J.M. Evaluation of corn hybrids expressing Cry1F (Herculex I Insect Protection) against fall armyworm (Lepidoptera: Noctuidae) in the southern United States. Journal of Entomological Science, v.43, p.41-51, $2008 \mathrm{~b}$.

WAQUIL, J.M.; VIANA, P.A.; LORDELLO, A.I.; CRUZ, I.; OLIVEIRA, A.C. Controle da lagarta do cartucho em milho com inseticidas químicos e biológicos. Pesquisa Agropecuária Brasileira, v.17, n.2, p.163-166, 1982.

WAQUIL, J.M.; FERREIRA VILLELA, F.M.; FOSTER, J.E. Resistance of Bt transgenic maize (Zea mays L.) to fall armyworm, Spodoptera frugiperda (Smith) (Lepidoptera: Noctuidae). Revista Brasileira de Milho e Sorgo, v.1, p.111, 2002.

Recebido em 19/1/12

Aceito em 19/4/13 